\title{
PKR Inhibition Rescues Memory Deficit and ATF4 Overexpression in ApoE $\varepsilon 4$ Human Replacement Mice
}

\author{
Yifat Segev, ${ }^{1 \star}$ Iliana Barrera, ${ }^{1 \star}$ Hadile Ounallah-Saad, ${ }^{1}$ Karin Wibrand,${ }^{3}$ Ida Sporild, ${ }^{3}$ Adva Livne, ${ }^{1}$ Tali Rosenberg, ${ }^{1}$ \\ Orit David, ${ }^{1}$ Meshi Mints, ${ }^{1}$ Clive R. Bramham, ${ }^{3}$ and Kobi Rosenblum ${ }^{1,2}$ \\ ${ }^{1}$ Sagol Department of Neurobiology and ${ }^{2}$ Center for Gene Manipulation in the Brain, University of Haifa, Haifa 3498838, Israel, and ${ }^{3}$ Department of \\ Biomedicine and KG Jebsen Centre for Research on Neuropsyhiatric Disorders, University of Bergen, N-5009 Bergen, Norway
}

Sporadic Alzheimer's disease (AD) is an incurable neurodegenerative disease with clear pathological hallmarks, brain dysfunction, and unknown etiology. Here, we tested the hypothesis that there is a link between genetic risk factors for AD, cellular metabolic stress, and transcription/translation regulation. In addition, we aimed at reversing the memory impairment observed in a mouse model of sporadic $\mathrm{AD}$. We have previously demonstrated that the most prevalent genetic risk factor for $\mathrm{AD}$, the ApoE4 allele, is correlated with increased phosphorylation of the translation factor eIF $2 \alpha$. In the present study, we tested the possible involvement of additional members of the eIF2 $\alpha$ pathway and identified increased mRNA expression of negative transcription factor ATF4 (aka CREB2) both in human and a mouse model expressing the human ApoE4 allele. Furthermore, injection of a PKR inhibitor rescued memory impairment and attenuated ATF4 mRNA increased expression in the ApoE4 mice. The results propose a new mechanism by which ApoE4 affects brain function and further suggest that inhibition of PKR is a way to restore ATF4 overexpression and memory impairment in early stages of sporadic AD.

Key words: Alzheimer's disease; ATF4; cognitive enhancer; memory consolidation; translation regulation

Significance Statement

ATF4 mRNA relative quantities are elevated in ApoE4 allele carriers compared with noncarrier controls. This is true also for the ApoE $\varepsilon 4$ human replacement mice. ApoE4 mice injected with PKR inhibitor (PKRi) demonstrate a significant reduction in ATF4 expression levels $3 \mathrm{~h}$ after one injection of PKRi. Treatment of ApoE4 human replacement mice with the PKRi before learning rescues the memory impairment of the ApoE4 AD model mice. We think that these results propose a new mechanism by which ApoE4 affects brain function and suggest that inhibition of PKR is a way to restore memory impairment in early stages of sporadic AD.

\section{Introduction}

Aging is the main risk factor for Alzheimer's disease (AD), which is known to progress for several years or even decades before appearance of the initial symptoms (Bishop et al., 2010; Sperling

Received Dec. 25, 2014; revised Aug. 3, 2015; accepted Aug. 6, 2015

Author contributions: Y.S., I.B., H.O.-S., C.R.B., and K.R. designed research; Y.S., I.B., H.O.-S., A.L., T.R., O.D., and M.M. performed research;Y.S., I.B., H.O.-S., K.W., I.S., A.L., T.R., O.D., and K.R. analyzed data; Y.S., I.B., C.R.B. and K.R. wrote the paper.

This work was supported by European Union Seventh Framework Program EUROSPIN (Contract HEALTH-F22009-241498), the German-Israeli Foundation DIP (R03971/1-1), Morasha (Israeli Science Foundation Legacy Heritage 1315/09), and the Wolfson charitable trust to K.R., H.-0.S. was supported by Ministry of Science and Technology Eshkol Fellowship. We thank members of the K.R. laboratory, specifically Dr. Shunit Gal Ben-Ari for critical reading of the manuscript and primary culture generation; and Drs. Vahram (Harry) Haroutunian and Joseph Buxbaum, Mt. Sinai School of Medicine, New York for the human brain tissue.

The authors declare no competing financial interests.

*Y.S. and I.B. contributed equally to this work.

Correspondence should be addressed to Dr. Kobi Rosenblum, Sagol Department of Neurobiology, Center for Gene Manipulation in the Brain, University of Haifa, Haifa 3498838, Israel. E-mail: kobir@psy.haifa.ac.il.

DOI:10.1523/JNEUROSCI.5241-14.2015

Copyright $\odot 2015$ the authors $\quad 0270-6474 / 15 / 3512986-08 \$ 15.00 / 0$ et al., 2011). Apolipoprotein $\varepsilon 4$ allele (ApoE4) has been largely associated with increased risk of the late-onset, sporadic $\mathrm{AD}$. The number of E4 copies carried is significantly associated with disease manifestation age, with E4/E4 carriers showing the earliest disease onset (Grossman et al., 2010). However, the underlying mechanisms by which ApoE4 enhances susceptibility to early onset of $\mathrm{AD}$ are unclear.

ApoE affects lipid metabolism in different ways, including regulation of lipid transport in the brain (Kim et al., 2009). The human ApoE gene has three polymorphic alleles, $\varepsilon 2$, $\varepsilon 3$, and $\varepsilon 4$, which differ from one another at residues 112 and 158 affecting their 3D structure (Mahley et al., 2006). The ApoEc4 allele has $\sim 20 \%$ prevalence in the general population and $>50 \%$ in the AD population (Rall et al., 1982; Strittmatter and Roses, 1996). ApoE is also a ligand for lipoprotein receptors and thus has an active role in maintenance of synaptic integrity and transmission by promoting amyloid- $\beta$ clearance and reversing NMDA receptor-dependent suppression caused by amyloid- $\beta$ peptide (Lauderback et al., 2001; Chen et al., 2010). ApoE4 variant 
promotes metabolic burden through several pathways, including oxidative stress, ER stress, inflammation, and mitochondrial dysfunction (Colton et al., 2002; Jofre-Monseny et al., 2008; Zhong et al., 2009).

A major cellular readout of diverse metabolic stress stimuli is the phosphorylation of eukaryotic initiation factor $2 \alpha$ (eIF $2 \alpha$ ) on Ser51, which functions as a switch for protein translation initiation rate. This process is controlled by different phosphatases and kinases, including double-stranded RNA-activated protein kinase (PKR), general control nonderepressible 2 (GCN2), and protein kinase $\mathrm{R}$ (PKR)-like endoplasmic reticulum kinase (PERK) (Trinh and Klann, 2013; Ounallah-Saad et al., 2014). Interestingly, the eIF $2 \alpha$ pathway governs the strength of memory consolidation, and the levels of eIF $2 \alpha$ phosphorylation, as well as PKR activation, are increased in several neurological disorders, including AD (Bullido et al., 2008; Gal-Ben-Ari et al., 2012; Moreno et al., 2012; Dumurgier et al., 2013; Kim et al., 2014) and AD mouse models (Page et al., 2006; Couturier et al., 2012; Segev et al., 2013). A recent study has shown that genetic manipulation of the eIF2 $\alpha$ kinases, PERK and GCN2, in APP-PS1 AD model restores synaptic deficits and improves memory impairment by reducing eIF $2 \alpha$ hyperphosphorylation and ATF4 expression (Ma et al., 2013). ATF4 links translation regulation with cAMP response element-binding protein (CREB) family-dependent transcription, which has been studied extensively for its essential role in normal and pathological learning and memory processes (Silva et al., 1998; Satoh et al., 2009; Kida and Serita, 2014). Recent work revealed both translational and transcriptional active roles of ATF4 in the development of AD pathology (Baleriola et al., 2014).

The ApoE AD transgenic mouse model, which harbors the human ApoE4 or ApoE3 under the murine ApoE promoter, is one of the few models to study sporadic AD (Hartman et al., 2001; Grootendorst et al., 2005; Bour et al., 2008). Using this model, we have previously shown that aging or carrying the ApoE4 allele promotes increased phosphorylation of eIF $2 \alpha$ in the forebrain, suggesting that genetic predisposition and aging converge on the eIF2 $\alpha$ pathway (Segev et al., 2013). Here, we tested the hypothesis that additional factors related to the eIF $2 \alpha$-pathway in mouse or human ApoE4 allele carriers are deregulated. Indeed, there are abnormal changes in ATF4 mRNA and protein expression in the ApoE4 carriers. Furthermore, inhibition of eIF $2 \alpha$ kinase, PKR, rescues the behavioral impairment phenotype and the increased ATF4 mRNA and protein levels in ApoE4 mice, introducing a potential novel treatment for cognitive impairment in sporadic AD patients.

\section{Materials and Methods}

Animals. Humanized knock-in ApoE3 (B6.129P2-ApoE ${ }^{\text {tm2 (ApoE*3) Mae }}$

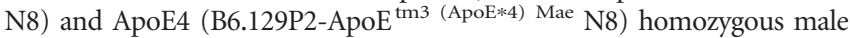
mice were supplied by Taconic Farms. Heterozygous mutants $\left(\right.$ eIF2 $\left.\alpha^{+/ 551 \mathrm{~A}}\right)$ were kindly donated by Prof. Nahum Sonenberg (McGill University). All cages were placed in a light- and temperature-controlled room, and behavioral tests were conducted during daylight hours. All animals were handled in accordance with the University of Haifa regulations and the National Institutes of Health Guidelines (Publication Number 8023), and maintained in a pathogen-free environment.

Animal treatment. All animal care and procedures were performed in accordance with local guidelines. Four-month-old ApoE3 and ApoE4 mice were injected intraperitoneally with a single dose of imidazolo-oxindole PKR inhibitor C-16 (PKRi; catalog \#527450; Calbiochem; $0.335 \mu \mathrm{g} / \mathrm{g}$ body weight, $\left.\mathrm{IC}_{50}=210 \mathrm{nM}\right)$. PKRi was prepared in DMSO (25 mM) and further diluted in saline to a final DMSO concentration of $0.5 \%$. Control mice were injected with $0.5 \%$ DMSO dissolved in saline solution.
Fear conditioning. Model chambers measuring $25 \times 25 \times 25 \mathrm{~cm}$ internally (Panlab, Harvard Apparatus) were located inside a larger, insulated plastic cabinet that excluded external light and noise. For the weak fearconditioning protocol, mice were placed in a chamber (with light $[20 \mathrm{~W}$ bulb] and a 16 bar metal grid floor) for $120 \mathrm{~s}$ after which the mice received a $2.9 \mathrm{kHz}$ tone, applied for $30 \mathrm{~s}$ at $80 \mathrm{~dB}$ (conditioned stimulus) and a subsequent $0.5 \mathrm{~mA}$ shock applied for $2 \mathrm{~s}$ (unconditioned stimulus), after which they remained in the chamber for 60 additional seconds. For a strong fear-conditioning protocol, the mice received two sequential tone-shock conditioning procedures separated by a $40 \mathrm{~s}$ interval. After the second tone, the mice remained in the chamber for 60 additional seconds. The chambers were cleaned with $10 \%$ ethanol between successive sets of mice. For context test $24 \mathrm{~h}$ and 1 week after conditioning, mice were placed in the conditioning chamber and kept in the cage for $300 \mathrm{~s}$ without tone or foot shock. Animal behavior was recorded, and the data were analyzed by Freeze Frame 3.0 software (Coulbourn Instruments). The indication for fear memory was percentage of time spent freezing.

Isolation of RNA and qRT-PCR of mice tissue. Total RNA $(1 \mu \mathrm{g})$ extraction from the hippocampus was performed using the RNAeasy Lipid Tissue mini kit (QIAGEN) according to the manufacturer's recommendations. Reverse transcription was performed using High Capacity cDNA Reverse Transcription kit (Applied Biosystem). Real-time PCR was performed with TaqMan universal PCR master mix (Applied Biosystems) in a total volume of $10 \mu \mathrm{l}$, using $2 \mu \mathrm{l}$ of cDNA and gene-specific "Assay on Demand" TaqMan reactions (Applied Biosystems). Real-time PCRs were performed in triplicates using the ABI PRISM StepOne plus Sequence Detector (Applied Biosystems) under the following conditions: $50^{\circ} \mathrm{C}$ for $2 \mathrm{~min}, 95^{\circ} \mathrm{C}$ for 10 min, and 40 cycles of $95^{\circ} \mathrm{C}$ for $15 \mathrm{~s}$ and $60^{\circ} \mathrm{C}$ for $1 \mathrm{~min}$. Threshold cycle $\left(\mathrm{C}_{\mathrm{t}}\right)$ values of the examined genes were normalized to the $C_{t}$ values of the mouse gpdh (Mm99999915_g1). The genes analyzed were as follows: DNA damage-inducible protein (gadd34/ppp1r15a; Mm00515325_g1), eif $2 \alpha\left(\mathrm{Mm} 01289723 \_\mathrm{m} 1\right)$, double-stranded RNA-activated protein kinase (pkr/eif2ak2; Mm01235643_m1), protein kinase R (PKR)-like endoplasmic reticulum kinase (perk/eif2ak3, Mm00438700_m1), general control nonderepressible-2 (gcn2/eif2ak4; Mm00469222_m1), activation transcription factor 4 (atf4; Mm00515325_g1), and C/EBP Homology protein (chop, Mn0113597_g1).

For human samples, total RNA $(1 \mu \mathrm{g})$ from Bm8 region was reverse transcribed using ImpromII (Promega) with random hexamers (MBI, Fermentas). $C_{t}$ values of the examined gene of interest (atf4, $\mathrm{Hs} 00909569-\mathrm{g} 1$ ) were normalized to the $\mathrm{C}_{\mathrm{t}}$ values of two housekeeping genes gusb and ipo8 (Hs99999908-m1 and Hs00183533-m1, respectively) in the $\varepsilon 4$ carrier and null allele control groups. Relative mRNA quantities were calculated for each sample separately using $2^{-\Delta \mathrm{Ct}}$ formula, and mRNA relative quantities for the test group (ApoE $\varepsilon 4$ carriers) was calculated using the $2^{-\Delta \Delta C t}$ formula. Statistical analyses were performed using $\Delta \mathrm{C}_{\mathrm{t}}$ values.

Human samples. Samples were received from the Brain Bank at Mt. Sinai School of Medicine, New York. The study included postmortem samples from a cross-section of 43 nursing home residents with clinical dementia rating (CDR) scale scores ranging from CDR0 (no dementia) to CDR1 (mild dementia). The subjects were either ApoE- $\varepsilon 4$ allele carriers ( $n=11,8$ women, 3 men, age range 67-96 years), or noncarrier controls ( $n=30,24$ women, 6 men, age range 69-98 years). Brain samples were taken from the superior frontal gyrus $(\mathrm{Bm} 8)$.

ISH. Mice were perfused with $4 \%$ PFA. Brains were removed and submerged sequentially in $4 \%$ PFA for $24 \mathrm{~h}$ at $4^{\circ} \mathrm{C}$ and $30 \%$ sucrose for $48 \mathrm{~h}$ at $4^{\circ} \mathrm{C}$. On the following day, the brains were rapidly frozen in 2-methyl butane and cooled to $-80^{\circ} \mathrm{C} ; 30-\mu \mathrm{m}$-thick coronal sections were cut on a Leica CM3050S cryostat using Richard-Allan Sec5e blades. Sections were immediately stored in a phosphate buffer containing $0.1 \%$ azide at $4^{\circ} \mathrm{C}$. For ATF4 ISH, riboprobes were prepared from genomic mouse DNA using the following PCR primers: forward-ATF4 (5'CCTTCGAGTTAAGCACATTCCT- $\left.3^{\prime}\right)$ and reverse-ATF4 (5'-TTTC TAGCTCCTTACACTCGCC-3'), generating a 979-nt-long PCR product that was cloned into the pCRII vector (Invitrogen). Antisense and sense probes were transcribed from linearized plasmids using T7 and SP6 polymerase in the presence of digoxigenin (DIG) labeling mix (Roche Diagnostics) according to the manufacturer's instructions. ISH was per- 
formed on $30-\mu \mathrm{m}$-thick floating sections, as described previously (Wibrand et al., 2006). To visualize the hybridization, the chromogenic substrates NBT/BCIP were used (Roche). Imaging was done using a Nikon Eclipse E600 microscope equipped with a $4 \times$ objective and the acquisition software NIS-Elements AR (Nikon Instruments). Microscopy images were analyzed using the open source software ImageJ (http://imagej.nih.gov/ij/). The average of the mean intensity of the staining was obtained for each hippocampal subfield and the background was subtracted before calculating the reciprocal values $(n=4)$.

Hippocampal slice preparation. After decapitation, mouse brain was immediately immersed in cold $\left(4^{\circ} \mathrm{C}\right)$ carboxygenated $\left(95 \% \mathrm{O}_{2}, 5 \% \mathrm{CO}_{2}\right)$ ACSF, which comprised $124 \mathrm{~mm} \mathrm{NaCl}, 5 \mathrm{~mm} \mathrm{KCl}, 1.2 \mathrm{~mm} \mathrm{MgSO}_{4}, 1.2$ $\mathrm{mm} \mathrm{NaH}{ }_{2} \mathrm{PO}_{4}, 26 \mathrm{~mm} \mathrm{NaHCO}_{3}, 10 \mathrm{~mm}$ D-glucose, and $2.4 \mathrm{~mm} \mathrm{CaCl}_{2}$. After $2 \mathrm{~min}$, both hippocampi were dissected out in a plate filled with cold $\left(4^{\circ} \mathrm{C}\right)$ ACSF on ice. The hippocampi were then put on a cooled stand of a McIlwain tissue chopper TC752 (Campden Instruments), cut into $400 \mu \mathrm{m}$ slices, and then put back into a chamber filled with cold $\left(4^{\circ} \mathrm{C}\right)$ carboxygenated ACSF. The hippocampal slices were kept in six different chambers at room temperature for $2 \mathrm{~h}$ before any pharmacological intervention ( 3 chambers for ApoE3 and 3 for ApoE4); each chamber contained six slices. Within each experiment, two chambers (one for ApoE3 and another for ApoE4) were used as a positive control for the quality of the slices, by infusing the chambers with $0.5 \%$ DMSO in ACSF, and the remaining four chambers were the experimental chambers. PKRi (catalog \#527450; Calbiochem) was dissolved in DMSO and further diluted in ACSF to a final DMSO concentration of $0.5 \%$. Each chamber was incubated with the $50 \mu \mathrm{M}$ PKRi for $3 \mathrm{~h}$.

Western blot analysis. Aliquots of the homogenate samples in SDS sample buffer were subjected to SDS-PAGE and Western blot analysis. After electrophoresis and electroblotting, the blots were blocked in freshly prepared Tris-buffered saline solution containing $0.1 \%$ Tween 20 (TBST) with $2 \%-5 \%$ BSA for $1 \mathrm{~h}$ at room temperature, with agitation. The blots were incubated with primary antibody overnight at $4^{\circ} \mathrm{C}$. After three 5 min washes with TBST, the blots were incubated for $1 \mathrm{~h}$ at room temperature with HRP-conjugated antibody $(1: 10,000)$ (GE Healthcare). The blots were then washed three times in TBST and exposed to enhanced chemiluminescence with the 20-500-120 EZ ECL kit (Biological Industries). Blots were exposed in ChemiDox XRS (Bio-Rad) and analyzed by Quantity-One 4.5.0 software (Bio-Rad). The following antibodies were used for Western blot analysis: ATF4 1:500 (D4B8) rabbit $\mathrm{mAb} \# 11815$ (Cell Signaling Technology) and $\beta$-actin 1:12,000 (Santa Cruz Biotechnology).

Statistical analysis. Statistical analyses were performed with IBM SPSS Statistics 19 software and GraphPad Prism6. Means of two groups were compared with a two-tailed $t$ test or the Mann-Whitney-Wilcoxon $U$ test. Comparisons of multiple groups or measurements were analyzed with one-way ANOVA or two-way ANOVA, respectively, followed by the appropriate post hoc tests.

\section{Results}

Human-ApoE4 targeted replacement mice exhibit prolonged mild cognitive impairment in contextual fear conditioning To better define memory impairment in young ApoE4 AD model mice, we first replicated the differential hippocampal-dependent behavioral phenotype of young male (4-6 months) ApoE4 and ApoE3 mice, observed previously (Hartman et al., 2001; Grootendorst et al., 2005; Bour et al., 2008; Segev et al., 2013). As expected, ApoE4 mice did not differ in freezing percentage in the conditioning phase $\left(F_{(1,35)}=0.12, p=0.73\right.$; two-way repeatedmeasures ANOVA; Fig. 1A). However, they displayed mild cognitive impairment-like behavior in contextual fear memory $24 \mathrm{~h}$ after conditioning (ApoE4, $n=22$; ApoE3, $n=15 ; t_{(24.1)}=3.03$, $p=0.006$; Fig. $1 B$ ).

To elucidate whether the memory deficiency remains apparent at a later time point reminiscent of consolidation (Daumas et al., 2005; Ji and Maren, 2008), we tested the mice using both a stronger protocol (two consecutive tone-shocks as opposed to one) and a longer time interval between conditioning and the retrieval test ( 1 week as opposed to $24 \mathrm{~h}$; Fig. 1C-E). Indeed, memory impairment of young ApoE4 mice was perceptible both $24 \mathrm{~h}$ (ApoE4, $n=8$; ApoE3, $n=6 ; t_{(6.4)}=3.8, p=0.008$; Fig. $1 D$ ) and 1 week (ApoE4, $n=8$; ApoE3, $n=6 ; t_{(5.9)}=2.7, p=0.04$; Fig. $1 E)$ after conditioning. There were no differences in freezing percentage of the tone test $\left(F_{(1,12)}=0.84, p=0.38\right.$; two-way repeated-measures ANOVA; data not shown), consistent with previous studies (Hartman et al., 2001; Grootendorst et al., 2005; Bour et al., 2008; Segev et al., 2013). These results suggest that the memory impairment in the ApoE4 mice in the contextual fear conditioning behavioral paradigm is strong and consistent; therefore, this was the test studied throughout the paper.

\section{Differential and region-specific expression of ATF4 mRNA in ApoE4 mice and human samples}

ApoE4 mice express higher phosphorylation levels of eIF $2 \alpha$ compared with ApoE3 controls (Segev et al., 2013). We hypothesized that ApoEs4 allele-dependent constitutive multifactorial metabolic burden, mirrored in part by activation of the eIF $2 \alpha$ pathway, may induce transcriptional changes in eIF $2 \alpha$ pathway genes (Baird and Wek, 2012). qRT-PCR revealed an $\sim 40 \%$ increase in the expression of ATF4 mRNA in ApoE4 mice (ApoE4, $n=10$; ApoE3, $n=8 ; t_{(16)}=7.06, p<0.0001 ;$ Fig. $\left.2 A\right)$. In contrast, other eIF2 $\alpha$ pathway genes examined were not differentially expressed (Fig. 2A), for example, growth arrest and DNA damage-inducible protein ( gadd34/ppp1r15a; $t_{(16)}=1.22, p=0.2$ ), eif2 $\alpha$ (ApoE4, $n=10$; ApoE3, $n=8 ; Z=-0.8, p=0.42$; Mann-Whitney test), and eIF2 $\alpha$-kinases: pkr/eif2ak2 $\left(t_{(16)}=0.254, p=0.8\right)$; PKR-like endoplasmic reticulum kinase (perk/eif2ak3; $t_{(16)}=-0.152, p=$ $0.9)$; and general control nonderepressible-2 (gcn2/eif2ak4; $t_{(16)}$ $=0.65, p=0.5$ ). As one of the direct targets of ATF4, we also analyzed CHOP/GADD153 mRNA relative expression (Gachon et al., 2001). Although not significant, chop expression showed a tendency to a decrease in the ApoE4 hippocampus $\left(t_{(16)}=1.818\right.$ $p=0.0878$ ).

To find whether the changes in transcription levels of ATF4 are ApoE4- and not ApoE3-dependent, we compared ATF4 mRNA levels in the hippocampus of ApoE4 and ApoE3 mice with those in the WT background C57BL/6 mice. Indeed, ApoE4 mice expressed significantly higher ATF4 levels compared with both control strains (ApoE4, $n=4$; ApoE3, $n=8, p=0.0001$; C57BL/6, $n=4, p=0.02 ; F_{(2,13)}=19.5, p=0.0001$, one-way ANOVA with Scheffé's pairwise comparisons; Fig. $2 B$ ).

Next, we compared the relative mRNA levels of ATF4 in young and old (4 and 12 months old, respectively) ApoE4 and ApoE3-control mice. Similarly to higher eIF2 $\alpha$ phosphorylation levels in aged ApoE3 and young ApoE4 mice (Segev et al., 2013), aged ApoE3 mice showed a significant increase in ATF4 mRNA levels compared with young ApoE3 mice (aged ApoE3, $n=3$; young ApoE3, $n=8 ; p=0.001$ ). In addition, although young ApoE4 mice differed from aged ApoE4 mice (young ApoE4, $n=$ 10; aged ApoE4, $n=5 ; p=0.03$; Fig. $2 C$ ), there were no significant differences between young ApoE4 and aged ApoE3 mice $(p=0.46)$. This further suggests that young ApoE4 mice display a premature aging-like phenotype reflected in activation of the eIF2 $\alpha /$ ATF 4 pathway. The statistical analysis reflects both a strain effect $\left(F_{(1,22)}=9.07, p=0.006\right)$ as well as an age effect $\left(F_{(1,22)}=\right.$ 27.65, $p<0.0001$; two-way ANOVA with Tukey pairwise comparisons).

To further test our hypothesis linking chronic upregulation of eIF2 $\alpha$ phosphorylation and transcription of ATF4, we analyzed ATF4 mRNA levels in the hippocampus of eIF2 $\alpha$ heterozygous 
A

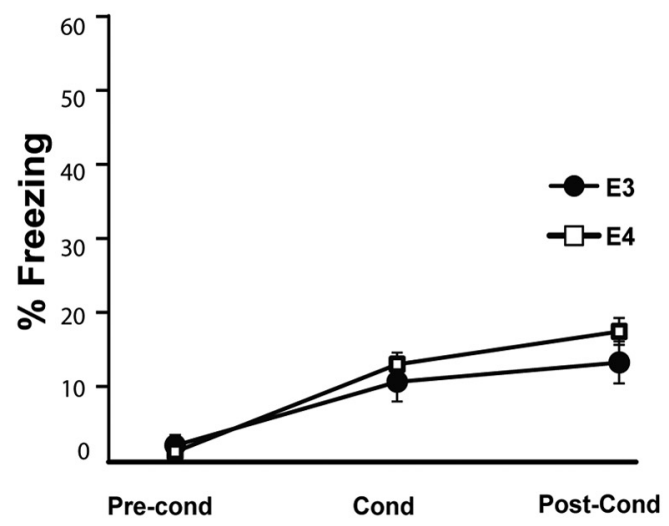

C

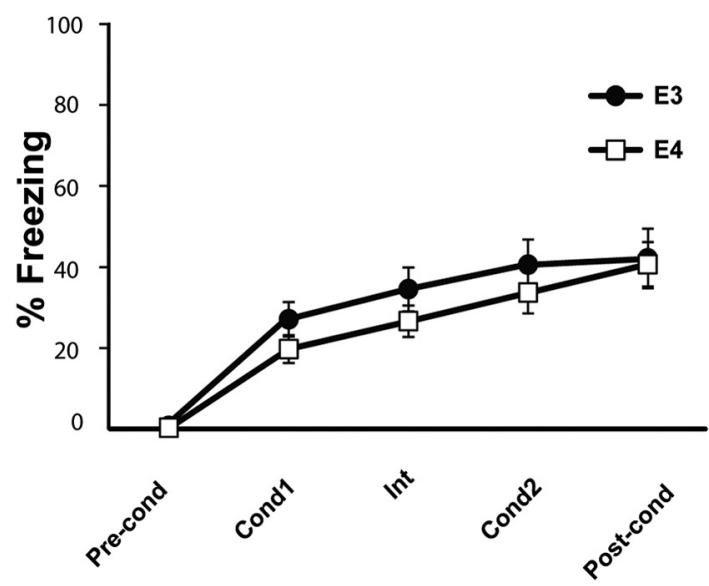

B

\author{
Context-24h
}

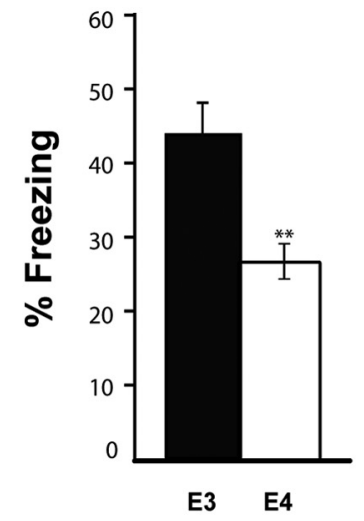

D

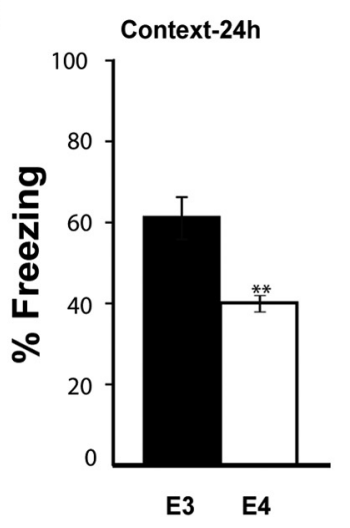

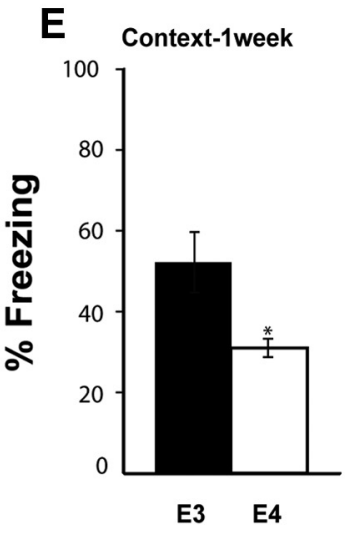

Figure 1. Human-ApoE4-targeted replacement mice show prolonged mild cognitive impairment in contextual fear conditioning. $A$, Conditioning; young (4-6 months) ApoE4 ( $n=22)$ and $\operatorname{ApoE3}(n=15)$ mice were trained in a weak contextual fear conditioning paradigm. There are no significant changes between groups in freezing percentage $(p=0.73) . \boldsymbol{B}$, Context test; $24 \mathrm{~h}$ after conditioning, the mice used for the weak contextual fear conditioning paradigm $(\boldsymbol{A})$ were tested for contextual memory by placing them in the conditioning chamber. ApoE4 mice show significantly lower freezing percentage than ApoE3 control mice. ${ }^{* *} p=0.006$. C, Conditioning; young ApoE4 $(n=8)$ and ApoE3 $(n=6)$ mice were trained in a strong contextual fear conditioning paradigm. There are no significant changes between groups in freezing percentage $(p=0.38)$. D, At $24 \mathrm{~h}$ after conditioning, the mice used in Cwere tested for contextual memory by placing them in the same chamber as the conditioning chamber. ApoE4 mice show significantly lower freezing percentage than ApoE3 age-matched controls. ${ }^{* *} p=0.008$. E, At 1 week after conditioning, mice were tested again for contextual memory and freezing was evaluated. ApoE4 mice show significantly lower freezing in the context test, compared with ApoE3 age-matched controls. ${ }^{*} p=0.04$. Data are mean \pm SEM. ${ }^{*} p<0.05 .{ }^{* *} p<0.01$. A, C, Repeated-measures ANOVA. B, D, E, $t$ test.

mutant $\left(e I F 2 \alpha^{+/ S 51 \mathrm{~A}}\right)$ mice, in which $e I F 2 \alpha$ phosphorylation and ATF4 translation are reduced and cognition is enhanced (CostaMattioli et al., 2007). Indeed, eIF $2 \alpha$-KI mice expressed significantly lower ATF4 mRNA levels in the hippocampus compared with WT littermates (eIF2 $\alpha-K I, n=11$; eIF2 $\alpha$-WT, $n=9 ; t_{(18)}=$ $2.4, p=0.03$; Fig. $2 D$ ), surprisingly demonstrating that a prolonged reduction in phosphorylation levels of eIF $2 \alpha$ has a bidirectional effect specifically on the transcription of ATF4 (Jiang et al., 2010; Trinh et al., 2012).

To strengthen our findings and to address the spatial distribution of ATF4-increased transcription levels within different subfields of the hippocampus, we used ISH on coronal hippocampal sections of young ApoE4 and ApoE3 mice. In addition to differential expression of ATF4 within the different subfields of the hippocampus both in ApoE4 and ApoE3 mice $\left(F_{(2,48)}=61.7, p<\right.$ 0.0001; two-way repeated-measures ANOVA with Sidak's pairwise comparisons), ApoE4 mice showed significantly higher ATF4 levels specifically in the CA1 region of the hippocampus compared with those in ApoE3 mice (ApoE4, $n=13$; ApoE3, $n=$ $13 ; p=0.044$; Fig. $2 E, F)$. Sample size in this experiment reflects the number of slices quantified from $n=4$ animals from each strain group.

The intriguing results in the $\mathrm{AD}$ model mice suggested a correlation between expression of the ApoE4 allele and ATF4 mRNA in the human brain. To test this hypothesis, we measured ATF4 mRNA expression levels in cDNA samples derived from postmortem human brains, using qRT-PCR. The region examined was the superior frontal gyrus (Bm8), which is known to be highly affected in $\mathrm{AD}$ (Sadigh-Eteghad et al., 2014). Interestingly, ATF4 mRNA levels are elevated 1.8-fold in ApoE4 allele carriers possessing either one or two copies of the allele $(n=11)$ compared with non-ApoE4 allele carrier $(n=31)$ controls $\left(t_{(15.57)}=-2.21, p=0.04\right.$; Fig. $\left.2 G\right)$, thus further demonstrating a link between ApoE4 and CREB regulation of transcription via ATF4.

PKR-inhibition rescues memory impairment in ApoE4 mice and reduces ATF4 mRNA and protein levels in the hippocampus

Assuming metabolic burden imposed by the ApoE4 allele is manifested at least in part by increased eIF2 $\alpha$ phosphorylation (Segev 
A

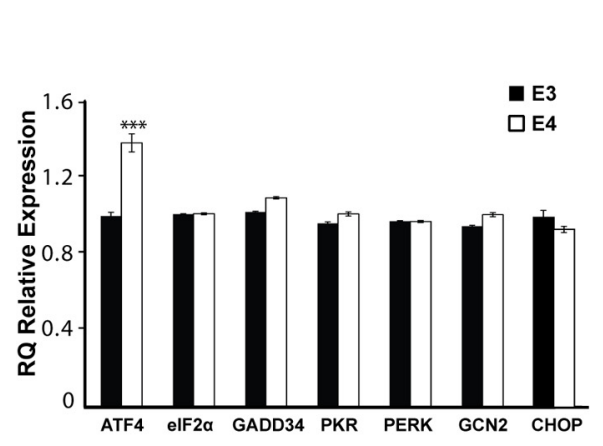

B

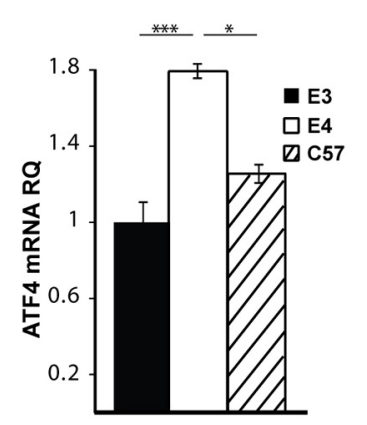

C

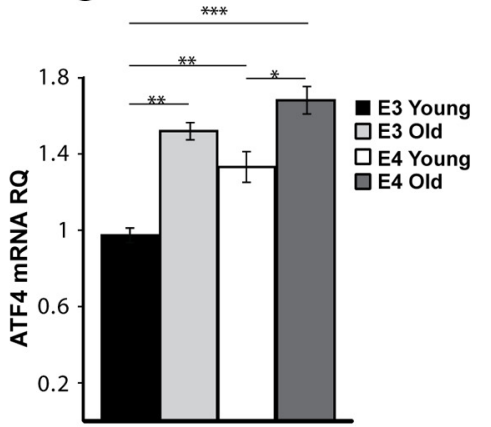

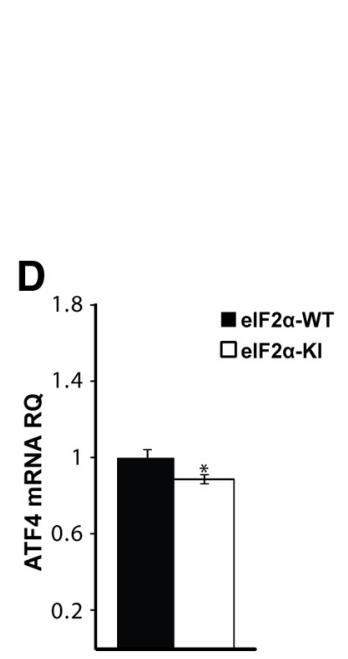

E ApoE3

ApoE4

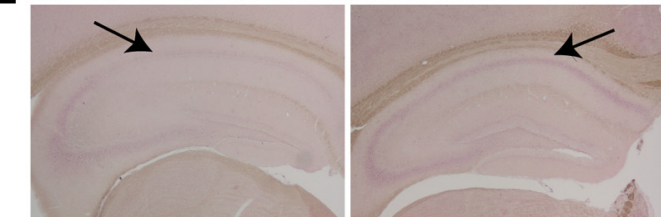

$\mathbf{F}$
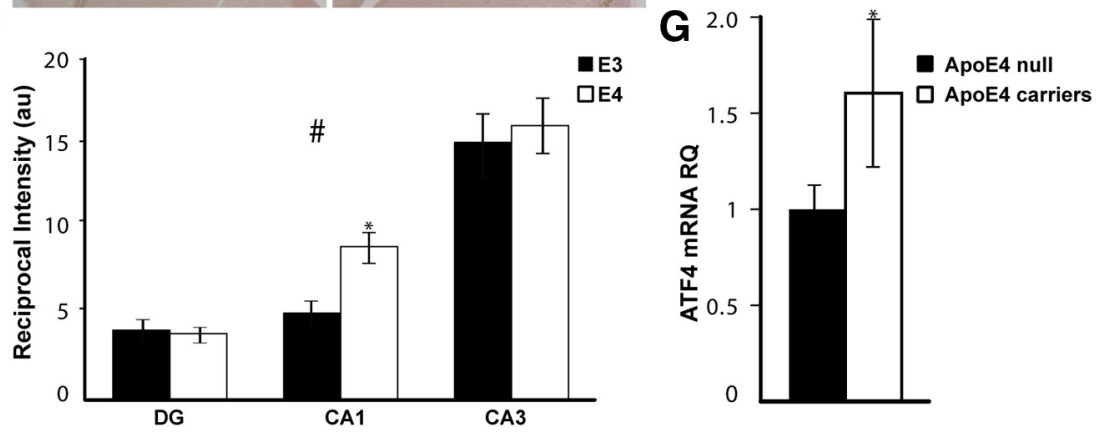

Figure 2. Differential and region-specific expression of ATF4 mRNA in the hippocampus in human-ApoE Tg mice and human samples. $A$, Whole hippocampal tissue of young ApoE4 ( $n=10)$ mice and ApoE3 $(n=8)$ age-matched controls was assessed for elF2 pathway-related mRNA factors. ApoE4 mice show significantly increased ATF4 mRNA levels $\left(* * * p=2.7 \times 10^{-6}\right)$. No differences in the mRNA levels of GADD34, PKR, PERK, GCN2, CHOP, and elF2 $\alpha$ were observed. $B$, ATF4 mRNA levels in the hippocampus of ApoE3 $(n=8)$ and ApoE4 $(n=4)$ mice were compared with those in C57BL/6 $(n=4)$ mice. ApoE4 ATF4 mRNA levels are significantly higher than ApoE3 $\left({ }^{* * *} p=0.0001\right)$ and $\left(57 \mathrm{BL} / 6\left({ }^{*} p=0.02\right)\right.$. No significant differences were observed between the two control groups. C, The mRNA levels of ATF4 are significantly increased in the hippocampus of aged ApoE3 $(n=5)$ mice $\left({ }^{* *} p=0.001\right)$ to a higher extent than in aged ApoE4 mice $\left({ }^{*} p=0.03\right)$, compared with strain-matched controls. There are no significant differences in ATF4 mRNA levels between young ApoE4 and aged ApoE3 hippocampus $(p=0.46)$. D, elF2 $\alpha$ mice ( 4 months; $n=11)$ have significantly decreased mRNA levels of ATF4 in the hippocampus compared with age-matched elF $2 \alpha$-WT controls $\left(n=9 ;{ }^{*} p=0.03\right)$. E, RNA ISH was performed on coronal hippocampal sections using digoxigenin-labeled RNA probes against ATF4 mRNA. Two representative images are shown. Arrowheads point to the CA1 region of the hippocampus where a difference in ATF4 mRNA expression is observed between the two mouse strains. $F$, Quantification of the mean intensity of ATF4 mRNA staining in cell body layers of the DG, CA1, and CA3 subfields of the hippocampus are reported as arbitrary units (a.u.) of reciprocal intensity. ATF4 mRNA distribution across hippocampal layers varies between the DG, CA1, and CA3, in both ApoE3 ( $n=13)$ and ApoE4 ( $n=13)$ ( ${ }^{*} p<$ 0.0001). CA1 ATF4 mRNA staining is significantly increased in ApoE4 ( $\left.{ }^{*} p=0.044\right)$. G, ATF4 mRNA relative quantities (RQ) in CDNA from postmortem brains are increased in ApoE4 carriers $(n=11)$ versus noncarriers $\left(n=31\right.$, age range 67-98 years) $\left(^{*} p=0.04\right)$. gusb and ipo8 were used as endogenous controls. RQ was calculated for each sample using the $2^{\wedge}-\Delta c t$ formula. Data are mean $\mathrm{RQ} / \mathrm{au} \pm \Delta \mathrm{C}_{\mathrm{t}} / \mathrm{SEM} .{ }^{*} p<0.05 .{ }^{* *} p<0.01$. ${ }^{* * *} p<0.001 . \boldsymbol{A}, \boldsymbol{D}, \boldsymbol{G}, t$ test. $\boldsymbol{B}$, One-way ANOVA with Scheffé's post hoc comparisons. C, Two-way ANOVA with Tukey pairwise comparisons. $\boldsymbol{F}$, Repeated-measures ANOVA.

et al., 2013; Ohno, 2014) and accounts to some degree for the cognitive deficiency, we aimed to rescue the impaired behavioral phenotype of ApoE4 mice observed, by interfering with the eIF $2 \alpha$ kinase PKR. PKRi has been previously referred to as a cognitive enhancer (Zhu et al., 2011; Stern et al., 2013); therefore, we expected the inhibitor to enhance cognition in the ApoE3 control group. For this purpose, ApoE3 mice were injected intraperitoneally with PKRi (PKRi; C-16, $0.335 \mu \mathrm{g} / \mathrm{g}$ body weight in $0.9 \%$ saline and $0.5 \%$ DMSO) $1 \mathrm{~h}$ before training in the fear conditioning paradigm using the standard one tone-shock protocol. For control, ApoE3 mice were injected with vehicle $(0.9 \%$ saline, $0.5 \%$ DMSO). Interestingly, PKRi did not have an effect on 1 week long-term contextual memory (PKRi, $n=14$; vehicle, $n=$ $21 ; t_{(33)}=0.36, p=0.72$ ) in ApoE3-treated mice (Fig. $3 A$ ). This could be explained by a ceiling effect in the behavior of this mouse strain, which does not allow them to improve their freezing percentage.
However, using the same experimental settings, ApoE4 PKRitreated mice showed improvement in the 1 week long-term contextual memory paradigm compared with ApoE4 vehicle-treated mice (PKRi, $n=15$; vehicle, $n=16$; $t_{(29)}=2.62, p=0.01$; Fig. $3 B)$. PKRi did not affect the freezing percentage in the conditioning phase (data not shown).

In parallel, we aimed at testing the link between the PKR/ eIF2 $\alpha$ pathway and ATF4 transcription and translation in the ApoE4 model. Toward that end, ApoE4 mice were injected intraperitoneally with PKRi, and hippocampal ATF4-mRNA levels were examined. For control, additional ApoE4 and ApoE3 groups were injected with vehicle. As shown above, here too, basal hippocampal mRNA levels of ATF4 were highly increased in ApoE4 compared with ApoE3 mice (ApoE3 vehicle, $n=6$; ApoE4 vehicle, $n=7 ; p<0.0001$; Fig. $3 C$ ). In addition, ApoE4 mice injected with PKRi demonstrated a small but significant reduction in hippocampal ATF4 mRNA expression levels $3 \mathrm{~h}$ 
A

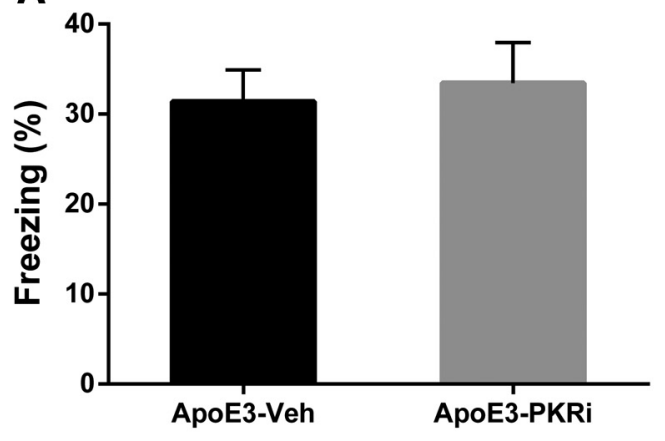

C

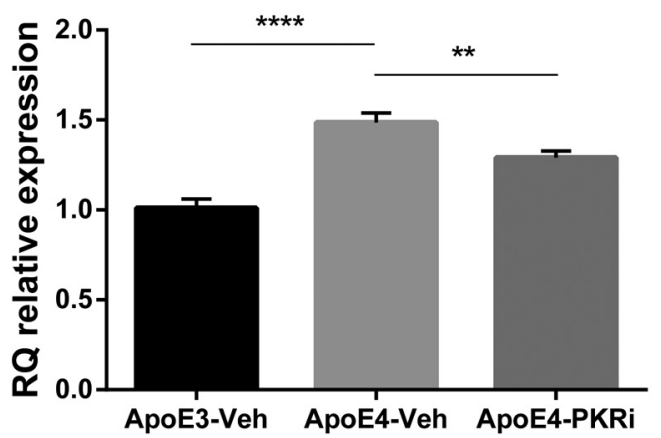

B

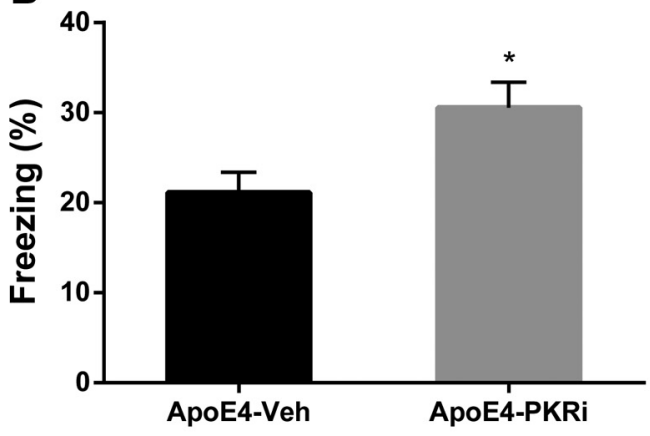

E3 E4 $\overline{\text { E3 E4 }}$

D

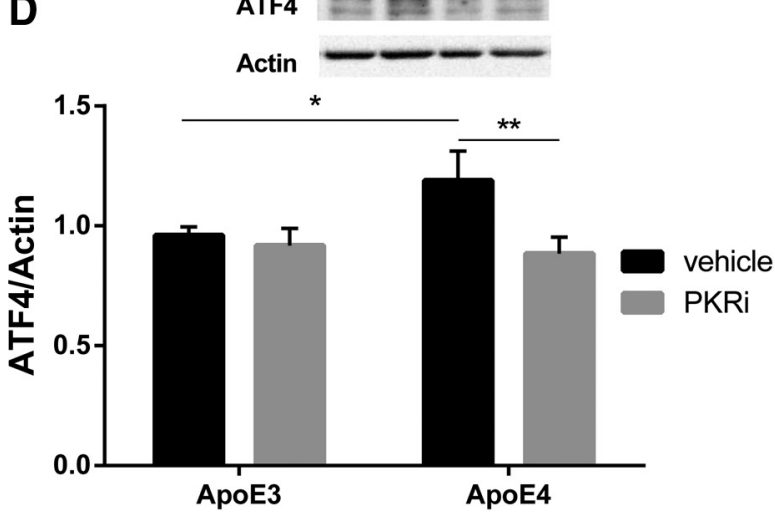

Figure 3. PKR inhibition rescues memory impairment in ApoE4 mice and reduces ATF4 mRNA and protein levels in the hippocampus. ApoE4 and ApoE3 (4-5 months) mice were injected intraperitoneally with a PKRi $(n=15)$ or vehicle $(n=16-22)$, at a dose of $0.335 \mu \mathrm{g} / \mathrm{g}$ body weight, $1 \mathrm{~h}$ before conditioning in a weak contextual fear conditioning paradigm, in two separate experiments for each strain. $\boldsymbol{A}$, ApoE3-treated mice do not differ significantly from ApoE3 vehicle ( $p=0.72)$, in the context test 1 week after training. $\boldsymbol{B}$, ApoE4 PKR-injected mice show significant increase in the freezing levels compared with ApoE4 vehicle. ${ }^{*} p=0.01$. C, ApoE4 mice were injected intraperitoneally with PKRi ( $\left.n=7\right)$, and their hippocampus was harvested $3 \mathrm{~h}$ after injection for evaluation of ATF4 mRNA levels. For control, ApoE4 $(n=7)$ and ApoE3 $(n=8)$ were injected with vehicle. In addition to increased mRNA expression in ApoE4 hippocampus compared with ApoE3 $\left({ }^{* * *} p<0.0001\right)$, PKRi significantly reduced mRNA levels in ApoE4-treated group compared with ApoE4 vehicle $\left({ }^{* *} p=0.007\right)$. D, ApoE4 vehicle hippocampal slices express higher ATF4-protein levels compared with ApoE3 vehicle slices (ApoE4-veh, $n=18$; ApoE3-veh, $n=20$ ). ${ }^{*} p=0.04$. PKRi decreases protein levels of ATF4 in ApoE4 hippocampal slices compared with ApoE4 vehicle slices (ApoE4-PKRi, $n=19) .{ }^{* *} p=0.009$. Data are mean RQ/Mean $\pm \Delta C_{t} / S E M .{ }^{*} p<0.05 .{ }^{* *} p<0.01 .{ }^{* * *} p<0.001$. A, B, $t$ test. C, One-way ANOVA with LSD post hoc comparisons. $\boldsymbol{D}$, Tw0-way ANOVA with Fisher's LSD pairwise comparisons.

after a single injection of PKRi (ApoE4 PKRi, $n=7$; ApoE4 vehicle, $n=7 ; p=0.007 ; F_{(2,17)}=25.43, p<0.0001$; one-way ANOVA with Fisher's LSD pairwise comparison; Fig. $3 C$ ).

Next, we assessed the effect of PKRi on hippocampal protein levels of ATF4, using hippocampal slice tissue. Freshly dissected hippocampal slices from ApoE3 and ApoE4 mice were immersed in ACSF and kept for $2 \mathrm{~h}$ before any pharmacological manipulation. Then the hippocampal slices were infused with vehicle (i.e., $0.5 \%$ DMSO) or with $50 \mu \mathrm{M}$ PKRi in $0.5 \%$ DMSO for $3 \mathrm{~h}$. Western blot analysis revealed increased ATF4 protein levels in vehicle-treated hippocampal slices of ApoE4 compared with ApoE3 mice (ApoE4 vehicle, $n=18$; ApoE3 vehicle, $n=20 ; p=$ 0.04 ; Fig. $3 D$ ). In addition, PKRi treatment significantly reduced ATF4 levels in the ApoE4 mice (ApoE4-PKRi, $n=19 ; p=0.009$ ), comparable to levels of vehicle-treated ApoE3 mice ( $p=0.49$; Fig. 3D). This experiment clearly demonstrates a significant PKRi effect $\left(F_{(1,72)}=4.86, p=0.031\right.$; two-way ANOVA with Fisher's LSD pairwise comparisons). Sample size here represents the number of slices dissected from 7 animals from each strain type.

No apparent changes between ApoE3 and ApoE4 mice were detected in hippocampal levels of PERK phosphorylation, protein expression of GADD34, or the PKR activator PACT (data not shown).

\section{Discussion}

The newly identified convergence of molecular machinery underlying memory consolidation and readout of cellular/neuronal metabolic stress suggest that eIF $2 \alpha$ phosphorylation, as a key valve controlling translation initiation rate, is involved in both processes. Thus, it may serve as a causal link between prolonged metabolic stress and neurodegenerative diseases (O'Connor et al., 2008; Segev et al., 2013; Halliday et al., 2014). In accordance with this line, we establish for the first time, to our knowledge, that the ApoE4 allele, the most significant genetic factor in sporadic $\mathrm{AD}$, known to promote multifactorial metabolic stress, converges on the eIF $2 \alpha /$ ATF 4 pathway both in a mouse model and the human brain.

Surprisingly, ATF4 abnormal expression in ApoE4 carriers is apparent not only as expected in protein level but also on the transcriptional level. Strengthening this is the finding that eIF2 $\alpha$-KI mice, known to express low ATF4 protein levels (CostaMattioli et al., 2007), possess similarly lower ATF4 mRNA levels in the hippocampus, suggesting bidirectional regulation of ATF4 mRNA levels by phosphorylation of eIF $2 \alpha$. The transcription factor ATF4 is a repressor of CREB-mediated gene expression, known to be an essential activator of gene expression required for 
the formation of long-term memory (Trinh et al., 2012). Furthermore, ATF4 has been described as playing an important role in normal brain physiology (Frank et al., 2010), as well as in the integrated stress response (Lange et al., 2008; Baleriola et al., 2014). ATF4 is subjected to both translational and transcriptional regulation by diverse stress stimuli. For example, ATF4 transcription is activated by amino acid deprivation, glucose starvation, and ER stress (Baird and Wek, 2012). The recently reported link between ApoE4 and the increase of nuclear import of class II histone deacetylase (HDAC4 and HDAC6) (Sen et al., 2015) could explain the levels of ATF4 mRNA by epigenetic changes in ATF4 promoter, although further studies will be necessary to investigate this possibility.

Our present findings open a new angle of research regarding ApoE4 metabolic and cognitive burden in young carriers. Most importantly, the cognitive disruption apparent in the ApoE4 model, as well as increased mRNA and protein expression of ATF4, is reversed via inhibition of PKR. Different groups have focused on intervention of eIF2/PKR-related pathways, however, mainly in relation to amyloid- $\beta$ pathology in familial-AD mice models (Lourenco et al., 2013; Ma et al., 2013). In the present study, we analyzed the outcome of inhibiting this pathway in a model of sporadic AD, ApoE4 mouse model, and its effect on the cognitive decline of the disease. This was approached using the fear conditioning paradigm, which showed the strongest differences between the ApoE mouse strains. Other groups have described additional behavioral paradigms in which ApoE4 mice are deficient (Kornecook et al., 2010; Salomon-Zimri et al., 2014). It would be interesting to further extend the behavioral effects of PKRi on these additional tests. In addition to the behavioral effect, we found that a single PKRi injection is sufficient to induce a small but significant reduction in ATF4 mRNA in ApoE4 mice after3 h.

The ISH results suggest that different brain regions are differentially affected by genetic predisposition; and specifically, CA1 may play an important role in the p-eIF $2 \alpha / \mathrm{ATF} 4$ integrated stress response of ApoE4 carriers. It would be intriguing to further measure the differential expression of ATF4 in the hippocampus of ApoE4 human and mouse carriers in specific cell types and subfields, such as the CA1. In our present study, we used for coherence male mice; however, further analysis should assess possible gender effects on the eIF $2 \alpha$-ATF4 pathway.

From a clinical perspective, it is important to note that PKR inhibition may be cognitively and metabolically beneficial also in an eIF2 $\alpha$-independent pathway (Carvalho et al., 2013; Nakamura et al., 2014) in normal aged and in the $\mathrm{AD}$ population, due to its involvement in inflammation and insulin metabolism (Zhu et al., 2011; Couturier et al., 2012; Stern et al., 2013). Furthermore, we cannot exclude the possibility that ApoE4-dependent ATF4 transcription is only partially regulated by $\mathrm{PKR} / \mathrm{eIF} 2$ pathway activation and that PKRi enhances memory via additional pathways. One may expect that intervention with the PKR pathway may lead to changes in general protein translation. Although this may indeed be one of the outcomes, our results strengthen the growing hypothesis suggesting that memory-dependent PKR/eIF $2 \alpha$ regulation depends more on transcription or translation of particular genes, most probably in specific neuronal types, than on the overall levels of general translation (Jiang et al., 2010). This group showed that pharmacologic specific activation of PKR in the CA1 did not have an effect on de novo general protein synthesis but rather had a specific increase of a small subset of genes, such as atf4.
Specifically targeting ATF4 via viral injections to either knock down ATF4 or overexpress CREB may be an additional tool to overcome the memory deficiency observed in this $\mathrm{AD}$ mouse model. However, due to the importance of ATF4 in diverse pathways in normal physiology, this issue should be carefully addressed (Trinh and Klann, 2013; Pasini et al., 2015).

Recent results, including ours, merit comprehensive screening for genetic risk factors for age-associated cognitive impairment of genes encoding for different translation factors and regulators. Moreover, this study opens new avenues for early treatment of mild cognitive impairment in the normal aged population and $\mathrm{AD}$ patients.

\section{References}

Baird TD, Wek RC (2012) Eukaryotic initiation factor 2 phosphorylation and translational control in metabolism. Adv Nutr 3:307-321. CrossRef Medline

Baleriola J, Walker CA, Jean YY, Crary JF, Troy CM, Nagy PL, Hengst U (2014) Axonally synthesized ATF4 transmits a neurodegenerative signal across brain regions. Cell 158:1159-1172. CrossRef Medline

Bishop NA, Lu T, Yankner BA (2010) Neural mechanisms of ageing and cognitive decline. Nature 464:529-535. CrossRef Medline

Bour A, Grootendorst J, Vogel E, Kelche C, Dodart JC, Bales K, Moreau PH, Sullivan PM, Mathis C (2008) Middle-aged human apoE4 targetedreplacement mice show retention deficits on a wide range of spatial memory tasks. Behav Brain Res 193:174-182. CrossRef Medline

Bullido MJ, Martínez-García A, Tenorio R, Sastre I, Muñnoz DG, Frank A, Valdivieso F (2008) Double stranded RNA activated EIF2 alpha kinase (EIF2AK2; PKR) is associated with Alzheimer's disease. Neurobiol Aging 29:1160-1166. CrossRef Medline

Carvalho BM, Oliveira AG, Ueno M, Araujo TG, Guadagnini D, CarvalhoFilho MA, Geloneze B, Lima MM, Pareja JC, Carvalheira JB, Saad MJ (2013) Modulation of double-stranded RNA-activated protein kinase in insulin sensitive tissues of obese humans. Obesity (Silver Spring) 21: 2452-2457. CrossRef Medline

Chen Y, Durakoglugil MS, Xian X, Herz J (2010) ApoE4 reduces glutamate receptor function and synaptic plasticity by selectively impairing ApoE receptor recycling. Proc Natl Acad Sci U S A 107:12011-12016. CrossRef Medline

Colton CA, Brown CM, Cook D, Needham LK, Xu Q, Czapiga M, Saunders AM, Schmechel DE, Rasheed K, Vitek MP (2002) APOE and the regulation of microglial nitric oxide production: a link between genetic risk and oxidative stress. Neurobiol Aging 23:777-785. CrossRef Medline

Costa-Mattioli M, Gobert D, Stern E, Gamache K, Colina R, Cuello C, Sossin W, Kaufman R, Pelletier J, Rosenblum K, Krnjević K, Lacaille JC, Nader K, Sonenberg N (2007) eIF2alpha phosphorylation bidirectionally regulates the switch from short- to long-term synaptic plasticity and memory. Cell 129:195-206. CrossRef Medline

Couturier J, Paccalin M, Lafay-Chebassier C, Chalon S, Ingrand I, Pinguet J, Pontcharraud R, Guillard O, Fauconneau B, Page G (2012) Pharmacological inhibition of PKR in APPswePS1dE9 mice transiently prevents inflammation at 12 months of age but increases Abeta 42 levels in the late stages of the Alzheimer's disease. Curr Alzheimer Res 9:344-360. CrossRef Medline

Daumas S, Halley H, Francés B, Lassalle JM (2005) Encoding, consolidation, and retrieval of contextual memory: differential involvement of dorsal CA3 and CA1 hippocampal subregions. Learn Mem 12:375-382. CrossRef Medline

Dumurgier J, Mouton-Liger F, Lapalus P, Prevot M, Laplanche JL, Hugon J, Paquet C, Groupe d'Investigation du Liquide Cephalorachidien Study N (2013) Cerebrospinal fluid PKR level predicts cognitive decline in Alzheimer's disease. PLoS One 8:e53587. CrossRef Medline

Frank CL, Ge X, Xie Z, Zhou Y, Tsai LH (2010) Control of activating transcription factor 4 (ATF4) persistence by multisite phosphorylation impacts cell cycle progression and neurogenesis. J Biol Chem 285:33324-33337. CrossRef Medline

Gachon F, Gaudray G, Thébault S, Basbous J, Koffi JA, Devaux C, Mesnard J (2001) The cAMP response element binding protein-2 (CREB-2) can interact with the C/EBP-homologous protein (CHOP). FEBS Lett 502: 57-62. CrossRef Medline

Gal-Ben-Ari S, Kenney JW, Ounalla-Saad H, Taha E, David O, Levitan D, 
Gildish I, Panja D, Pai B, Wibrand K, Simpson TI, Proud CG, Bramham CR, Armstrong JD, Rosenblum K (2012) Consolidation and translation regulation. Learn Mem 19:410-422. CrossRef Medline

Grootendorst J, Bour A, Vogel E, Kelche C, Sullivan PM, Dodart JC, Bales K, Mathis C (2005) Human apoE targeted replacement mouse lines: h-apoE4 and h-apoE3 mice differ on spatial memory performance and avoidance behavior. Behav Brain Res 159:1-14. CrossRef Medline

Grossman I, Lutz MW, Crenshaw DG, Saunders AM, Burns DK, Roses AD (2010) Alzheimer's disease: diagnostics, prognostics and the road to prevention. EPMA J 1:293-303. CrossRef Medline

Halliday M, Radford H, Mallucci GR (2014) Prions: generation and spread versus neurotoxicity. J Biol Chem 289:19862-19868. CrossRef Medline

Hartman RE, Wozniak DF, Nardi A, Olney JW, Sartorius L, Holtzman DM (2001) Behavioral phenotyping of GFAP-apoE3 and -apoE4 transgenic mice: apoE4 mice show profound working memory impairments in the absence of Alzheimer's-like neuropathology. Exp Neurol 170:326-344. CrossRef Medline

Ji J, Maren S (2008) Differential roles for hippocampal areas CA1 and CA3 in the contextual encoding and retrieval of extinguished fear. Learn Mem 15:244-251. CrossRef Medline

Jiang Z, Belforte JE, Lu Y, Yabe Y, Pickel J, Smith CB, Je HS, Lu B, Nakazawa K (2010) eIF2alpha phosphorylation-dependent translation in CA1 pyramidal cells impairs hippocampal memory consolidation without affecting general translation. J Neurosci 30:2582-2594. CrossRef Medline

Jofre-Monseny L, Minihane AM, Rimbach G (2008) Impact of apoE genotype on oxidative stress, inflammation and disease risk. Mol Nutr Food Res 52:131-145. CrossRef Medline

Kida S, Serita T (2014) Functional roles of CREB as a positive regulator in the formation and enhancement of memory. Brain Res Bull 105:17-24. CrossRef Medline

Kim HJ, Raphael AR, LaDow ES, McGurk L, Weber RA, Trojanowski JQ, Lee VM, Finkbeiner S, Gitler AD, Bonini NM (2014) Therapeutic modulation of eIF2alpha phosphorylation rescues TDP-43 toxicity in amyotrophic lateral sclerosis disease models. Nat Genet 46:152-160. CrossRef Medline

Kim J, Basak JM, Holtzman DM (2009) The role of apolipoprotein E in Alzheimer's disease. Neuron 63:287-303. CrossRef Medline

Kornecook TJ, McKinney AP, Ferguson MT, Dodart JC (2010) Isoformspecific effects of apolipoprotein $\mathrm{E}$ on cognitive performance in targetedreplacement mice overexpressing human APP. Genes Brain Behav 9: 182-192. CrossRef Medline

Lange PS, Chavez JC, Pinto JT, Coppola G, Sun CW, Townes TM, Geschwind DH, Ratan RR (2008) ATF4 is an oxidative stress-inducible, prodeath transcription factor in neurons in vitro and in vivo. J Exp Med 205:12271242. CrossRef Medline

Lauderback CM, Hackett JM, Keller JN, Varadarajan S, Szweda L, Kindy M, Markesbery WR, Butterfield DA (2001) Vulnerability of synaptosomes from apoE knock-out mice to structural and oxidative modifications induced by A beta(1-40): implications for Alzheimer's disease. Biochemistry 40:2548-2554. CrossRef Medline

Lourenco MV, Clarke JR, Frozza RL, Bomfim TR, Forny-Germano L, Batista AF, Sathler LB, Brito-Moreira J, Amaral OB, Silva CA, Freitas-Correa L, Espírito-Santo S, Campello-Costa P, Houzel JC, Klein WL, Holscher C, Carvalheira JB, Silva AM, Velloso LA, Munoz DP, et al. (2013) TNFalpha mediates PKR-dependent memory impairment and brain IRS-1 inhibition induced by Alzheimer's beta-amyloid oligomers in mice and monkeys. Cell Metab 18:831-843. CrossRef Medline

Ma T, Trinh MA, Wexler AJ, Bourbon C, Gatti E, Pierre P, Cavener DR, Klann E (2013) Suppression of eIF2alpha kinases alleviates Alzheimer's disease-related plasticity and memory deficits. Nat Neurosci 16:1299-1305. CrossRef Medline

Mahley RW, Weisgraber KH, Huang Y (2006) Apolipoprotein E4: a causative factor and therapeutic target in neuropathology, including Alzheimer's disease. Proc Natl Acad Sci U S A 103:5644-5651. CrossRef Medline

Moreno JA, Radford H, Peretti D, Steinert JR, Verity N, Martin MG, Halliday M, Morgan J, Dinsdale D, Ortori CA, Barrett DA, Tsaytler P, Bertolotti A, Willis AE, Bushell M, Mallucci GR (2012) Sustained translational repression by eIF2alpha-P mediates prion neurodegeneration. Nature 485: 507-511. CrossRef Medline

Nakamura T, Arduini A, Baccaro B, Furuhashi M, Hotamisligil GS (2014) Small-molecule inhibitors of PKR improve glucose homeostasis in obese diabetic mice. Diabetes 63:526-534. CrossRef Medline
O'Connor T, Sadleir KR, Maus E, Velliquette RA, Zhao J, Cole SL, Eimer WA, Hitt B, Bembinster LA, Lammich S, Lichtenthaler SF, Hébert SS, De Strooper B, Haass C, Bennett DA, Vassar R (2008) Phosphorylation of the translation initiation factor eIF2alpha increases BACE1 levels and promotes amyloidogenesis. Neuron 60:988-1009. CrossRef Medline

Ohno M (2014) Roles of eIF2alpha kinases in the pathogenesis of Alzheimer's disease. Front Mol Neurosci 7:22. CrossRef Medline

Ounallah-Saad H, Sharma V, Edry E, Rosenblum K (2014) Genetic or pharmacological reduction of PERK enhances cortical-dependent taste learning. J Neurosci 34:14624-14632. CrossRef Medline

Page G, Rioux Bilan A, Ingrand S, Lafay-Chebassier C, Pain S, Perault Pochat MC, Bouras C, Bayer T, Hugon J (2006) Activated double-stranded RNA-dependent protein kinase and neuronal death in models of Alzheimer's disease. Neuroscience 139:1343-1354. CrossRef Medline

Pasini S, Corona C, Liu J, Greene LA, Shelanski ML (2015) Specific downregulation of hippocampal ATF4 reveals a necessary role in synaptic plasticity and memory. Cell Rep 11:183-191. CrossRef Medline

Rall SC Jr, Weisgraber KH, Mahley RW (1982) Human apolipoprotein E: the complete amino acid sequence. J Biol Chem 257:4171-4178. Medline

Sadigh-Eteghad S, Majdi A, Farhoudi M, Talebi M, Mahmoudi J (2014) Different patterns of brain activation in normal aging and Alzheimer's disease from cognitional sight: meta analysis using activation likelihood estimation. J Neurol Sci 343:159-166. CrossRef Medline

Salomon-Zimri S, Boehm-Cagan A, Liraz O, Michaelson DM (2014) Hippocampus-related cognitive impairments in young apoE4 targeted replacement mice. Neurodegener Dis 13:86-92. CrossRef Medline

Satoh J, Tabunoki H, Arima K (2009) Molecular network analysis suggests aberrant CREB-mediated gene regulation in the Alzheimer disease hippocampus. Dis Markers 27:239-252. CrossRef Medline

Segev Y, Michaelson DM, Rosenblum K (2013) ApoE epsilon4 is associated with eIF2alpha phosphorylation and impaired learning in young mice. Neurobiol Aging 34:863-872. CrossRef Medline

Sen A, Nelson TJ, Alkon DL (2015) ApoE4 and Abeta oligomers reduce BDNF expression via HDAC nuclear translocation. J Neurosci 35:75387551. CrossRef Medline

Silva AJ, Kogan JH, Frankland PW, Kida S (1998) CREB and memory. Annu Rev Neurosci 21:127-148. CrossRef Medline

Sperling RA, Aisen PS, Beckett LA, Bennett DA, Craft S, Fagan AM, Iwatsubo T, Jack CR Jr, Kaye J, Montine TJ, Park DC, Reiman EM, Rowe CC, Siemers E, Stern Y, Yaffe K, Carrillo MC, Thies B, Morrison-Bogorad M, Wagster MV, et al. (2011) Toward defining the preclinical stages of Alzheimer's disease: recommendations from the National Institute on Aging-Alzheimer's Association workgroups on diagnostic guidelines for Alzheimer's disease. Alzheimers Dement 7:280-292. CrossRef Medline

Stern E, Chinnakkaruppan A, David O, Sonenberg N, Rosenblum K (2013) Blocking the eIF2alpha kinase (PKR) enhances positive and negative forms of cortex-dependent taste memory. J Neurosci 33:2517-2525. CrossRef Medline

Strittmatter WJ, Roses AD (1996) Apolipoprotein E and Alzheimer's disease. Annu Rev Neurosci 19:53-77. CrossRef Medline

Trinh MA, Klann E (2013) Translational control by eIF2alpha kinases in long-lasting synaptic plasticity and long-term memory. Neurobiol Learn Mem 105:93-99. CrossRef Medline

Trinh MA, Kaphzan H, Wek RC, Pierre P, Cavener DR, Klann E (2012) Brain-specific disruption of the eIF2alpha kinase PERK decreases ATF4 expression and impairs behavioral flexibility. Cell Rep 1:676688. CrossRef Medline

Wibrand K, Messaoudi E, Håvik B, Steenslid V, Løvlie R, Steen VM, Bramham CR (2006) Identification of genes co-upregulated with Arc during BDNF-induced long-term potentiation in adult rat dentate gyrus in vivo. Eur J Neurosci 23:1501-1511. CrossRef Medline

Zhong N, Ramaswamy G, Weisgraber KH (2009) Apolipoprotein E4 domain interaction induces endoplasmic reticulum stress and impairs astrocyte function. J Biol Chem 284:27273-27280. CrossRef Medline

Zhu PJ, Huang W, Kalikulov D, Yoo JW, Placzek AN, Stoica L, Zhou H, Bell JC, Friedlander MJ, Krnjević K, Noebels JL, Costa-Mattioli M (2011) Suppression of PKR promotes network excitability and enhanced cognition by interferon-gamma-mediated disinhibition. Cell 147:1384-1396. CrossRef Medline 